\title{
O plágio para as Ciências Humanas
}

\author{
Fernando Miranda Arraz
}

\begin{abstract}
Resumo
O presente estudo objetiva analisar produções científicas brasileiras sobre a temática plágio em dissertações e teses na área de ciências humanas durante a última década (2010 a 2020), por meio de uma revisão integrativa da literatura, reunindo e sintetizando resultados de pesquisas sobre o tema abordado em questão, com intuito de desvelar a sua emergência e/ ou consolidação como objeto de investigação nessa área do conhecimento e no interior desse espaço acadêmico. As buscas foram executadas nas bases de dados virtuais: Biblioteca Digital Brasileira de Teses e Dissertações (BDTD) e no banco de dissertações e teses da CAPES. Concluiu-se que existe uma carência de investigações científicas sobre a questão do plágio nas áreas de ciências humanas, necessitando, assim, um olhar diferenciado dos pesquisadores para esta temática que é necessária para o nosso meio acadêmico.
\end{abstract}

Palavras-chave: Plágio. Revisão Integrativa. Dissertação. Teses.

* Pontifícia Universidade Católica de Minas Gerais (PUC Minas). Doutorando em Letras e Linguística. Analista Executivo de Defesa Social da Secretaria de Justiça e Segurança Pública de Minas Gerais (SEJUSP). ORCID: http://orcid.org/0000-0002-4609-7683.

Cadernos CESPUC de Pesquisa. Série Ensaios. n.39, $2^{\circ}$ Sem./2021, p. 88-108. e-ISSN: 2358-3231 (OJS). Recebido em: 05/11/2021. Aceito em: 15/12/2021. 


\title{
Plagiarism for the Human Sciences
}

\author{
Fernando Miranda Arraz
}

\begin{abstract}
This study aims to analyze Brazilian scientific production on the theme plagiarism in dissertations and theses in the human sciences area during the last decade (2010 to 2020), through an integrative literature review, gathering and synthesizing research results on the theme addressed in question, in order to unveil its emergence and/or consolidation as an object of investigation in this area of knowledge and within this academic space. The searches were performed in virtual databases: Brazilian Digital Library of Theses and Dissertations (BDTD) and in the CAPES dissertation and theses database. It was concluded that there is a lack of scientific investigations on the issue of plagiarism in the areas of human sciences, thus requiring a different look from researchers on this theme that is necessary for our academic environment.
\end{abstract}

Keywords: Plagiarism. Integrative Review. Dissertation. Theses. 


\section{Introdução}

O plágio constitui-se em transgressão dos direitos autorais e punições judiciais conforme a Lei 9.610/98 (BRASIL, 1998). Nesse caso, se constitui como amparo legal mediante providências regimentais nas instituições de ensino superior. Abordar a temática plágio não é algo comum nas pesquisas dos autores brasileiros, uma vez que diversos questionamentos aparecem, tais como os conceitos de autoria e a problemática dos direitos de propriedade intelectual. Neste sentido, discussões acerca do plágio nem sempre estão presentes na rotina pedagógica durante os cursos de graduação e pósgraduação, principalmente no que diz respeito às pesquisas de Mestrado e Doutorado, quando os discentes precisam criar suas dissertações e teses. Neste sentido, Silveira (2018) relata que não se torna viável uma possível discussão sobre este tema sem tratar de outras temáticas que permeiam este assunto, tais como: autor e autoria, ética e integridade na pesquisa, o professor como participante ativo na formação de alunos, bem como o papel da universidade nesses processos.

Durante a elaboração das produções intelectuais, a questão do plágio é uma temática que gera diversas discussões no meio acadêmico, sendo um dos requisitos com maior dificuldade para docentes e discentes, conforme as exigências de cada instituição que regulamentam as pesquisas científicas. Mediante as rotinas acadêmicas que precisam ser cumpridas, são reforçadas as exigências de produções intelectuais, bem como são continuamente monitoradas e auferida a sua devida autenticidade e o caráter fidedigno nos trabalhos acadêmicos.

Cabe ressaltar, que os discursos no meio acadêmico destacam a questão do "fazer" a produção intelectual, porém as técnicas que viabilizam esse arranjamento podem ser acessadas com extrema facilidade no meio tecnológico. No entanto, há dificuldades da ordem do saber, e os produtos nem sempre são concluídos a contento. Neste sentido, é necessário apresentar às dificuldades, reduzindo a um vaivém de configurações bem articuladas e legitimamente aceitas. 


\section{Plágio}

A partir de quando e por que razões passou-se da necessidade da imitação a infâmia do plágio? [...] Quando é que a língua, ordem transcendente à subjetividade, começou a ser objeto de reivindicação de propriedade? [...] (SCHNEIDER, 1990, p.42).

Poderíamos dizer que quem realiza o plágio não estaria fazendo uma nova criação? A resposta seria, não necessariamente, pois esse é um episódio que causa diversas discussões, pois essa seria mais uma possível resposta de forma serena e automática, uma vez que de fato, possa vir a fazer jus a uma maior reflexão para um debate mais apropriado. Conforme Simões (2012), o plágio é um termo que chega ao português pelo latim plagium, mas também tem origem do grego plagios, que significa o desencaminho de escravos por meios enviesados.

Na própria Constituição Federal brasileira, de 1988, já é possível encontrar em seu texto o amparo contra a cópia não permitida, pois nela se estabelece a garantia do direito de propriedade intelectual. Na nossa referida Constituição cidadã, consta que "aos autores pertence o direito exclusivo de utilização, publicação ou reprodução de suas obras, transmissível aos herdeiros pelo tempo que a lei fixar". ${ }^{1}$

A obra de Schneider (1990) Ladrões de palavras: ensaio sobre o plágio, a psicanálise e o pensamento, proporciona uma ampla discussão sobre a temática plágio, oferecendo análises mediante diversos ângulos, especialmente no que se refere a psicanálise. Ainda, de acordo com o autor supracitado, "no sentido moral, o plágio designa um comportamento refletido que visa ao emprego dos esforços alheios e à apropriação fraudulenta dos resultados intelectuais de seu trabalho" (SCHNEIDER, 1990, p.47). Neste sentido, para esse autor, quem realiza o plágio precisaria saber e ter plena consciência que sua atitude, além de ser errada é também desonesta.

A representação moral do plágio é histórica e socialmente condicionada. O plágio tem uma história. Mas essa história é complexa e contraditória: como tudo o

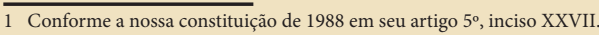


que concerne à concepção, ela não tem mais desenlaces do que começos. [...] O combate que travam o escritor e o plagiário no homem de letras, e que se manifesta brutalmente na consciência infeliz do autor moderno, já atormentava os Antigos (SCHNEIDER, 1990, p.49).

Conforme Judensnaider (2011a), o plágio é considerado como uma cópia de textos que não é da autoria do plagiador, uma vez que não foi realizada a referenciação. A cópia sem a sua devida citação, costuma ser interpretada como uma espécie de roubo/furto de informações e análises, visto que não foi ofertado o devido crédito ao trabalho desenvolvido pelo autor da obra, sendo caracterizado como uma apropriação da produção intelectual de outrem.

Segundo Lima (2013) é imprescindível realizar a distinção de forma clara e objetiva sobre as terminologias que abordam o plágio. O termo plágio engloba a prática e o desfrute de cópia de trabalho de outros autores, já a cópia não necessariamente diz respeito ao plágio. Este somente se refere à cópia, uma vez que não obedece à atribuição da respectiva fonte e do autor. Nesse sentido, o conceito de plágio implicaria em cópia, mas a cópia não precisa se configurar como plágio, pois pode vir adequadamente acompanhada de sua devida referência. Como podemos perceber, definir o termo plágio não é uma tarefa segura e pacífica, embora em muitas pesquisas acadêmicas, e até mesmo na legislação, a complexidade do termo nem sempre tem sido objeto de discussão entre pesquisadores e docentes.

De acordo com Bazerman (2010), a centralidade da questão sobre o plágio surge da tensão entre a reivindicação da propriedade intelectual e a produção cultural comum e coletiva. Devido à evidente expansão do uso da Internet, essa tensão teria intensificado a crise de importância do tema da cópia livre sem referência. O obstáculo seria devido à ambiguidade do papel desempenhado pelo crescimento da internet, que ora contribui para a aprendizagem escolar, por meio da evolução e aumento acesso à informação, ora facilita práticas fraudulentas nos trabalhos escolares e acadêmicos.

Nas reflexões de Schneider (1990) há um alerta sobre a questão de ponderarmos que as produções que o ser humano consegue como plágio, seriam um eufemismo. Segundo este mesmo autor, não existe, de fato originalidade e respeito entre sujeitos livres para trocar os produtos de seu intelecto, porém a citação poderia ser o recurso apresentado como 
uma espécie de solução, "a transição da língua de empréstimo para a língua própria, a ideia recebida e o pensamento novo." (SCHNEIDER, 1990, p.38).

\section{Plágio na academia}

O plágio não é entendido como um problema isolado do aluno, mas como uma realidade que diz respeito à instituição em sua totalidade e requer propostas de enfrentamento que tenham essa característica de globalidade, que envolvam os alunos, professores, orientadores e gestores (KROKOSCZ, 2011 p.752).

As exposições proporcionadas neste estudo têm a intenção de demonstrar reflexões e elucidações do plágio, sendo considerado um fenômeno antigo e que vem se despontando na sociedade em diferentes áreas e circunstâncias, mas que adquire contornos específicos no meio acadêmico. $\mathrm{O}$ autor citado na epígrafe aponta estudos que comprovam que a internet vem contribuindo para a disseminação do plágio e também conseguem demonstrar abordagens sobre a questão da incapacidade autoral:

Acredita-se ser relevante pensar-se em projetos/ações que estimulem o exercício da construção da autoria/autonomia na universidade. Torna-se vital a reflexão sobre a prática do plágio entre os graduandos, professores em formação, visto ser esse um problema que tem tomado proporções críticas, pois roubar de si mesmo a possibilidade de um outro pensar, da inventividade, é um preço muito caro que o sujeito tem a pagar (SILVA, 2008, p. 4).

Então, cabe destacar que os debates em torno da problemática do plágio no âmbito acadêmico diz respeito mais aos princípios éticos envolvidos, do que os aspectos jurídicos (cumprimento das leis). Desta forma, argumenta-se que uma pesquisa acadêmica cedida por terceiros é apresentada como sendo do próprio constituidor do plágio, é compreendida como uma fraude ou um ato de má-fé, que ocorre por quem recebe o trabalho. Sendo assim, acredita que o responsável autoral é o acadêmico que entrega a obra intelectual como própria, caracterizando materialmente 
suas aptidões e competências em relação ao conhecimento adquirido, mas que legitimamente não lhe pertence e muito menos o identifica.

A utilização indevida de escritos alheios reflete no contexto acadêmico, mediante apropriação de conhecimento materializado por outro, que pensa e registra. Da mesma forma que solicitam pleitear punições, as práticas infratoras apontam incapacidade na construção da própria produção. Neste cenário de complexidade e enfrentamentos, coexistem tanto infrações contra a autoria quanto ausências de naturalização na produção de ideias.

Nessa perspectiva, cada vez que a universidade ignora a necessidade de desenvolver projetos que idealizem práticas de leitura/escrita, com vistas à constituição da autonomia do discente para responder pelo que diz e escreve, faz com que estes estudantes se tornem à negatividade da consciência do outro, à negação da autoria, a identidade do outro e principalmente ao silenciamento como autor.

\section{Método através da revisão integrativa}

Mediante o presente estudo objetivamos analisar a produção científica brasileira sobre o plágio em dissertações e teses na área de ciências humanas, através de uma revisão integrativa da literatura, reunindo e sintetizando resultados de pesquisas sobre a temática abordada em questão, com intuito de desvelar a sua emergência e/ou consolidação como objeto de investigação nessa área do conhecimento e no interior desse espaço acadêmico.

A opção pelo método de revisão levou em consideração as colocações de Mendes et al. (2008), que apontam que a Revisão Integrativa de Literatura visa coletar e sintetizar resultados de pesquisas sobre uma determinada temática de forma sistemática e ordenada, colaborando assim para o aprofundamento das informações sobre a referida investigação, permitindo que os resultados venham a obter novos conhecimentos.

Nesta seara, a coleta dos dados foi registrada em planilhas por meio de instrumento elaborado pelo autor, durante os meses de setembro 
e outubro de 2021, por meio de busca online bibliográfica de publicações brasileiras na última década, entre 2010 a 2020.

No início da pesquisa a intenção era realizar a seleção de dissertações e teses em diversas áreas, porém devido ao cumprimento da exigência de limitação de páginas, optamos em trabalhar somente com a área das ciências humanas, por ainda ser um estudo carente de publicações e principalmente para trazer à cena e abrir discussões sobre o plágio nos estudos acadêmicos. Para seleção das dissertações e teses sobre a temática, utilizou-se nas buscas as seguintes palavras-chave: "plágio" e "autoria”. As buscas foram executadas nas bases de dados virtuais: Biblioteca Digital Brasileira de Teses e Dissertações (BDTD) e no banco de dissertações e teses da CAPES.

Os critérios de inclusão utilizados para a seleção da amostra foram: (1) teses e dissertações realizadas no Brasil; (2) teses e dissertações na área de ciências humanas. Os critérios de exclusão foram (1) publicações repetidas; (2) estudos não disponíveis na íntegra e (3) publicações que não apresentasse relação direta com a temática.

$\mathrm{Na}$ etapa de leitura na íntegra, excluímos os estudos que embora contemplassem no título ou resumo os descritores, não se aproximavam do tema do presente estudo, ou seja, dissertações e teses que não se enquadravam nos critérios de inclusão estabelecidos. Ao final foram selecionados sete publicações, sendo seis dissertações e somente uma tese que se referem de forma fidedigna a temática sobre o plágio. Ressalta-se que foi adotado o método descritivo para a devida análise das publicações. Frente ao exposto, o presente estudo objetiva identificar a produção científica atual sobre o assunto, permitindo uma melhor compreensão sobre o plágio e seus desdobramentos na área das ciências humanas.

\section{Resultados e discussão}

A temática deste estudo vem sendo alvo de muitas críticas tanto na academia, como também no meio midiático, estimulando reflexões através da visão do pesquisador, perpassando durante o processo de elaboração de sua produção intelectual entre os discentes, para que assim, seja impedido o plágio em seus estudos. A existência de disciplinas curriculares voltadas à 
elaboração de produções acadêmicas no início dos cursos, poderia ser uma das alternativas e possíveis garantias de que o conhecimento sobre construção e infração que cercam a questão do plágio seja do conhecimento dos jovens pesquisadores. Torna-se necessário e relevante realizar discussões e trazer subsídios na intenção de proporcionar diversos tipos de ponderações que venha a possibilitar discussões que auxiliem na prevenção e combate ao plágio na academia. Frente a essa realidade, não é espantoso ter vários casos de plágio na educação superior e que vem sendo explorados em noticiários e divulgados como infração a ser combatida por toda a sociedade.

Segundo Ferreira (2002), a compreensão do estado de conhecimento sobre um tema, em determinado momento, é necessária no processo de evolução da ciência, a fim de que se ordene periodicamente o conjunto de informações e resultados obtidos. Classificação esta que admita sugestão das possibilidades de conexão de diferentes aspectos, aparentemente independentes; a assimilação de duplicações ou contrassensos; e, a determinação de lacunas e obliquidades.

O presente estudo, enquanto subsídios científicos servirá para corroborar, prevenir e expandir as discussões acerca das problemáticas decorrentes do plágio. Assim, a realização deste estudo se torna de grande relevância, uma vez que os resultados obtidos podem gerar benefícios para o meio acadêmico e valorização dos autores que realizam suas próprias produções científicas.

Pensando em uma melhor maneira de entendimento e organização dos efeitos, optou-se pela organização dos principais resultados em forma de quadros, sendo os resultados obtidos analisados e discutidos. Após essa etapa, foram construídas as categorias, e dentro das categorias elaboradas, foi realizada a análise e discussão das publicações selecionadas. 
Quadro 1. Artigos publicados indexados nas bases de dados, a saber: procedência, títulos, autores e ano de publicação, Belo Horizonte, MG, 2021

\begin{tabular}{|c|c|c|c|}
\hline PROCEDÊNCIA & TÍTULOS & AUTORES & ANO \\
\hline 1) Mestrado & $\begin{array}{l}\text { A percepção docente sobre as } \\
\text { consequências do plágio para os } \\
\text { processos de ensino e aprendizagem } \\
\text { na universidade. }\end{array}$ & $\begin{array}{l}\text { FARINA, } \\
\text { Cassiamara }\end{array}$ & 2020 \\
\hline 2) Mestrado & $\begin{array}{l}\text { Escrita, plágio e autoria em produções } \\
\text { acadêmicas }\end{array}$ & $\begin{array}{l}\text { COSTA, Ana } \\
\text { Luiza Santos } \\
\text { da. }\end{array}$ & 2018 \\
\hline 3) Mestrado & $\begin{array}{l}\text { Plágio na academia: reflexões sobre a } \\
\text { integridade na pesquisa e a ética na } \\
\text { formação docente e discente }\end{array}$ & $\begin{array}{l}\text { SILVEIRA, } \\
\text { Zélia Pires da. }\end{array}$ & 2018 \\
\hline 4) Mestrado & $\begin{array}{l}\text { A abordagem do plágio nos livros } \\
\text { didáticos do ensino fundamental e na } \\
\text { visão de autores }\end{array}$ & $\begin{array}{l}\text { CASTRO, } \\
\text { Sirlene } \\
\text { Rodrigues } \\
\text { Ferreira }\end{array}$ & 2017 \\
\hline 5) Tese & $\begin{array}{l}\text { Outras palavras: análise dos conceitos } \\
\text { de autoria e plágio na produção textual } \\
\text { científica no contexto pós-moderno }\end{array}$ & $\begin{array}{l}\text { KROKOSCZ, } \\
\text { Marcelo. }\end{array}$ & 2014 \\
\hline 6) Mestrado & $\begin{array}{l}\text { Autoria e Plágio: representações } \\
\text { sociais na Educação Superior }\end{array}$ & $\begin{array}{l}\text { FREITAS, } \\
\text { Talita Cristiane } \\
\text { Sutter }\end{array}$ & 2013 \\
\hline 7) Mestrado & $\begin{array}{l}\text { Vozes diluídas, camufladas ou } \\
\text { exaltadas na fronteira entre a autoria } \\
\text { e o plágio }\end{array}$ & $\begin{array}{l}\text { DIAS, Wagner } \\
\text { Teixeira }\end{array}$ & 2013 \\
\hline
\end{tabular}

Fonte: Elaboração do autor (2021).

A apresentação do quadro 1, revela que as primeiras publicações na década pesquisada se deram no ano de 2013, mediante os trabalhos dos autores Dias (2013) e Freitas (2013), ambos apresentando dissertações, visando e objetivando discussões sobre autoria e plágio e também se 
referindo à educação superior. Nesse sentido, podemos inferir que a grande maioria, precisamente 6 (seis) produções são referentes à educação superior, ou seja produções na academia, e uma produção se refere à educação básica, sendo a produção de Castro (2017) tratando da questão do plágio nos livros didáticos do Ensino Fundamental. Sendo assim, a referida pesquisa sobre a temática apresentada em dissertações e teses, exibe-se como um apropriado indicador para uma melhor compreensão do método de constituição e desenvolvimento de um campo de conhecimento.

No entanto, durante a última década, a referida pesquisa demonstra que as produções publicadas com esta temática são escassas, uma vez que a abordagem do plágio na área de ciências humanas é considerada de grande relevância para o meio acadêmico. Pode-se verificar que, de acordo com o ano das publicações, foi observado que nos anos de 2013, 2014 e 2018, tiveram duas publicações em cada ano, sendo que todas são dissertações, com exceção de uma tese publicada em 2014.

No que se refere aos autores, podemos destacar Krokoscz (2014), que além de defender seu doutoramento, sendo a única tese na década sobre o tema plágio, o autor realiza uma avaliação sobre os conceitos de autoria e plágio nas produções acadêmicas em um contexto pós-moderno. A autora Farina (2020) também merece destaque pela sua defesa de Mestrado, por ser a última publicação da década referente à percepção docente sobre as consequências do plágio para os processos de ensino e aprendizagem na universidade, sendo considerada uma abordagem importantíssima para o combate desta temática no meio acadêmico.

Quadro 2. Publicações, programas e área de origem das publicações, Belo Horizonte, MG, 2021

\begin{tabular}{|l|l|l|}
\hline \multicolumn{1}{|c|}{ PUBLICAÇÕES } & \multicolumn{1}{|c|}{ PROGRAMAS } & \multicolumn{1}{c|}{ ÁREAS } \\
\hline $\begin{array}{l}\text { 1) UFG - Universidade } \\
\text { Federal de Goiás }\end{array}$ & $\begin{array}{l}\text { Programa de Pós-graduação } \\
\text { em Educação }\end{array}$ & $\begin{array}{l}\text { Políticas Educacionais, } \\
\text { Gestão e Formação de } \\
\text { Professores. }\end{array}$ \\
\hline $\begin{array}{l}\text { 2) UFTM - Universidade } \\
\text { Federal do Triângulo } \\
\text { Mineiro }\end{array}$ & $\begin{array}{l}\text { Programa de Pós-graduação } \\
\text { em Educação }\end{array}$ & $\begin{array}{l}\text { Fundamentos e Práticas } \\
\text { Educacionais }\end{array}$ \\
\hline $\begin{array}{l}\text { 3) UFMG- Universidade } \\
\text { Federal de Minas Gerais }\end{array}$ & $\begin{array}{l}\text { Programa de Pós-graduação } \\
\text { em Educação - Didática e } \\
\text { Docência }\end{array}$ & $\begin{array}{l}\text { Educação Tecnológica e } \\
\text { Sociedade }\end{array}$ \\
\hline
\end{tabular}




\begin{tabular}{|l|l|l|}
\hline $\begin{array}{l}\text { 4) UNB- Universidade de } \\
\text { Brasília }\end{array}$ & $\begin{array}{l}\text { Programa de Pós-graduação } \\
\text { em Educação }\end{array}$ & $\begin{array}{l}\text { Educação, Tecnologias e } \\
\text { Comunicação }\end{array}$ \\
\hline $\begin{array}{l}\text { 5) USP - Universidade de } \\
\text { São Paulo }\end{array}$ & $\begin{array}{l}\text { Programa de Pós-graduação } \\
\text { em Educação }\end{array}$ & $\begin{array}{l}\text { Ensino de Ciência e } \\
\text { Matemática }\end{array}$ \\
\hline $\begin{array}{l}\text { 6) FURB- Universidade } \\
\text { Regional de Blumenau }\end{array}$ & $\begin{array}{l}\text { Centro de Ciências da } \\
\text { Educação }\end{array}$ & Educação \\
\hline $\begin{array}{l}\text { 7) PUCRJ - Pontifícia } \\
\text { Universidade Católica do } \\
\text { Rio de Janeiro. }\end{array}$ & $\begin{array}{l}\text { Erograma de Pós-Graduação } \\
\text { em Educação }\end{array}$ \\
\hline
\end{tabular}

Fonte: Elaboração do autor (2021).

Em relação ao quadro 2, no que se refere aos estados de publicação, merece destaque Minas Gerais, como duas publicações, ambas com publicações de suas dissertações, sendo uma pela Universidade Federal de Minas Gerais (UFMG) no Programa de Pós-graduação em Educação Didática e Docência, sendo na área de Educação Tecnológica e Sociedade; e a outra publicação foi na Universidade Federal do Triângulo Mineiro (UFTM) no Programa de Pós-graduação em Educação Fundamentos e Práticas Educacionais.

No que se refere às áreas de atuação, todas os programas estão voltados para área de educação em diversificadas linhas de pesquisa. Podemos destacar a área de educação de Ensino de Ciências e Matemática da Universidade de São Paulo, sendo a única tese divulgada nesta década pesquisada. Cabe destacar, ainda, sobre a linha de pesquisa "educação tecnológica” que a aparecem nos estudos de Silveira (2018) e Castro (2017). 
Quadro 3. Objetivos dos artigos publicados e instrumentos utilizados Belo Horizonte, MG, 2021

\begin{tabular}{|c|c|}
\hline OBJETIVOS & $\begin{array}{l}\text { PROCEDIMENTOS } \\
\text { METODOLÓGICOS }\end{array}$ \\
\hline $\begin{array}{l}\text { 1) Compreender a percepção dos docentes } \\
\text { do curso de Direito de duas Instituições } \\
\text { de Ensino Superior (IES) acerca da } \\
\text { incidência de plágio em trabalhos } \\
\text { acadêmicos, bem como suas opiniões } \\
\text { sobre as consequências desta atitude para } \\
\text { o processo de ensino e aprendizagem e } \\
\text { futura atuação profissional. }\end{array}$ & $\begin{array}{l}\text { Foi realizada pesquisa descritiva, por } \\
\text { meio de investigação bibliográfica e de } \\
\text { campo, que contou com aplicação de } \\
\text { questionários. A análise foi por meio da } \\
\text { análise de conteúdo. }\end{array}$ \\
\hline $\begin{array}{l}\text { 2) Analisar aspectos da escrita que } \\
\text { os graduandos em Letras de distintas } \\
\text { universidades, situadas nas regiões Norte, } \\
\text { Nordeste e Sudeste, mobilizam para } \\
\text { construir suas produções acadêmicas. }\end{array}$ & $\begin{array}{l}\text { Baseada em uma análise documental, } \\
\text { tomando por base os sites dos programas } \\
\text { de pós-graduação stricto sensu. }\end{array}$ \\
\hline $\begin{array}{l}\text { 3) Avaliar a forma como os cursos de Pós- } \\
\text { graduação da Universidade Federal de } \\
\text { Minas Gerais (UFMG) têm enfrentado a } \\
\text { questão do plágio no desenvolvimento dos } \\
\text { trabalhos acadêmicos e quais as diretrizes } \\
\text { institucionais dos órgãos de deliberação } \\
\text { superior, referentes à prevenção e combate } \\
\text { ao plágio, aos direitos autorais e à ética } \\
\text { e integridade na pesquisa no âmbito da } \\
\text { Universidade, considerando o seu papel } \\
\text { institucional na formação dos alunos. }\end{array}$ & $\begin{array}{l}\text { Pesquisa indiciária que trata acerca da } \\
\text { complexidade do ato de escrever e ser } \\
\text { detentor de suas palavras em um contexto } \\
\text { de relação texto/discurso que exige } \\
\text { criticidade. }\end{array}$ \\
\hline $\begin{array}{l}\text { 4) Analisar criticamente a abordagem que } \\
\text { os livros didáticos de Português, Geografia, } \\
\text { Ciências e Matemática do } 6^{\circ} \text { ao } 9^{\circ} \text { ano } \\
\text { do ensino fundamental fazem de temas } \\
\text { relacionados ao plágio como orientação } \\
\text { na produção textual dos estudantes. }\end{array}$ & $\begin{array}{l}\text { Pesquisa de natureza exploratória, dentre } \\
\text { as técnicas, e a entrevista semiestruturada } \\
\text { como coleta de dados. A investigação fica } \\
\text { por meio da análise de conteúdo. }\end{array}$ \\
\hline
\end{tabular}




\begin{tabular}{|c|c|}
\hline $\begin{array}{l}\text { 5) Discutir as relações existentes entre } \\
\text { autoria e plágio e suas implicações no } \\
\text { âmbito da produção textual científica. }\end{array}$ & $\begin{array}{l}\text { Pesquisa teórica que discute as relações } \\
\text { existentes entre autoria e plágio e suas } \\
\text { implicações no âmbito da produção } \\
\text { textual científica. }\end{array}$ \\
\hline $\begin{array}{l}\text { 6) investigação ocupa-se em } \\
\text { compreender representações sociais } \\
\text { de autoria e plágio a partir de práticas } \\
\text { recorrentes de produção intelectual entre } \\
\text { docentes e discentes na educação superior. }\end{array}$ & $\begin{array}{l}\text { Pesquisa baseada na Teoria das } \\
\text { Representações Sociais (TRS). O } \\
\text { instrumento utilizado para a coleta de } \\
\text { dados foram questionários com entrevistas } \\
\text { abertas, sendo que a análise será por meio } \\
\text { da Análise de conteúdo. }\end{array}$ \\
\hline $\begin{array}{l}\text { 7) Buscou aferir como professores } \\
\text { universitários e licenciandos } \\
\text { compreendem e se relacionam com } \\
\text { questões que tangem o universo } \\
\text { fronteiriço da autoria e do plágio nos } \\
\text { trabalhos acadêmicos de pesquisa. }\end{array}$ & $\begin{array}{l}\text { Entrevista semiestruturada. A análise foi } \\
\text { realizada com o auxílio do software Atlas. } \\
\text { Ti, que permitiu uma análise decupada e } \\
\text { pormenorizada das entrevistas. }\end{array}$ \\
\hline
\end{tabular}

Fonte: Elaboração do autor (2021).

Em relação aos objetivos propostos nas pesquisas citadas, percebemos discussões importantes e necessárias sobre autoria e plágio, sendo uma temática abordada em três produções, visto que na tese de Krokoscz (2014) o autor apresenta uma pesquisa teórica que discute as relações existentes entre autoria e plágio e suas implicações no âmbito da produção textual científica. Na dissertação de Freitas (2013), a autora ocupase em compreender representações sociais de autoria e plágio a partir de práticas recorrentes de produção intelectual entre docentes e discentes na educação superior. Já o estudo de Dias (2013), busca aferir como docentes e discentes compreendem e se relacionam com questões que tangem o universo fronteiriço da autoria e do plágio nos trabalhos acadêmicos de pesquisa.

No que se refere aos procedimentos metodológicos e instrumentos para a coleta de dados nas pesquisas, podemos destacar que todos foram realizadas por uma abordagem qualitativa, porém em relação aos instrumentos de coleta de dados, podemos referenciar a entrevista semiestruturada nos estudos de Dias (2013) e Castro (2017). Já Freiras 
(2013) optou em realizar entrevistas abertas. Já em relação as análises da coleta de dados, a análise de conteúdo se sobressai, sendo abordada em três produções, Farina (2020), Castro (2017) e Freitas (2013).

\section{Quadro 4. Considerações finais, Belo Horizonte, MG, 2021}

\begin{tabular}{|l|}
\hline \multicolumn{1}{|c|}{ RESULTADOS } \\
\hline 1) Verificou-se que são desenvolvidas ações para prevenir, coibir e/ou punir a prática. \\
Identificou-se, também, que para a maior parte dos docentes pesquisados o plágio \\
é muito mais um problema ético do que fruto de desinformação dos alunos. Este \\
entendimento está em discordância com o referencial teórico, que apresenta o contexto \\
social como forte motivador do plágio.
\end{tabular}

2) Como resultados foram apresentados dados expressivos, uma vez que o plágio tem sido uma forma de escrita e vem ganhando mais espaço na universidade. A autora ainda ressalta que a autoria deve ocorrer nesse ambiente acadêmico, uma vez que é o espaço para desenvolver a construção do ser autor e detentor posicionamentos críticos.

3) A autora conclui que a UFMG não possui políticas institucionais de enfretamento e combate ao plágio, demonstrando a necessidade de promover ações para diagnosticar o plágio e tomar medidas educativas, preventivas e corretivas, de acordo com o caso.

4) Constatamos que o plágio não figurou como elemento necessário no livro didático e a autora infere que os autores não se ocupam da temática também por não ser exigência do PNLD.

5) As concepções de plágio e autoria científica na atualidade correspondem às formas desatualizadas de entender dois fenômenos correlacionados que não podem ser mais interpretados com as categorias que precedem a revolução digital.

6) Com o estudo realizado foi possível compreender motivos da ausência de autoria nas produções acadêmicas. A autoria, que não é recorrente nos trabalhos elaborados pelos acadêmicos, se desenvolve articulada por um conjunto de recortes de produção intelectual materializados nas obras por eles consultadas.

7) $\mathrm{O}$ autor conclui que nem todo plágio cometido por licenciandos se faz como forma de trapaça. Há desconhecimento e dúvida do que venha a configurar plágio, de modo que as construções autorais sejam prejudicadas.

Fonte: Elaboração do autor (2021). 
Em relação aos resultados obtidos nas pesquisas, podemos inferir que são trabalhos que realmente consideramos de suma importância para o combate e prevenção do plágio na academia. No trabalho de Farina (2020), constatou-se que a maioria dos docentes se depararam com textos de alunos que cometeram plágio, sendo considerado prejudiciais à aprendizagem, prejudicando tanto a produção intelectual dos estudantes quanto seu futuro desempenho profissional. Quando o plágio é apresentado na pesquisa científica, ele ocupa o espaço de uma nova perspectiva, de uma visão diferenciada, de informações que podem surgir e revelar novos caminhos.

No trabalho de Costa (2018), verificou-se que a prática do plágio impede a produção de conhecimento e dificulta o desenvolvimento da voz do discente. A autora também observou que as produções acadêmicas apresentam continuamente exemplares não referenciais, utilizando de truques para usar o plágio, em alguns casos até cópias completas. A autora conclui sua dissertação apontando que a escrita passou por mudanças consideráveis na contemporaneidade, uma vez que "os sujeitos envoltos pelo uso da tecnologia e facilidade com que o discurso do outro é posto apresentam a dificuldade de se tornarem autores de suas palavras" (COSTA, 2018, p. 93).

No estudo de Silveira (2018), os resultados das pesquisas demonstraram que, apesar da grande importância, essa temática não têm sido objeto de discussões na universidade, mas apenas em momentos específicos e pontuais. A autora ainda relata que para se combater o plágio no meio acadêmico deve ser pensado de forma institucional para o enfrentamento dessas questões, com a implicação das instituições, professores e alunos, ou seja, de todas as partes interessadas, a fim de criar um conjunto diretrizes que indiquem medidas preventivas e educacionais para minimizar essa problemática. Em face dos resultados da pesquisa, a autora revela "a falta de sistematicidade de ações institucionais para lidar com o problema do plágio no meio acadêmico, é necessário e primordial pensar na formação dos alunos e estabelecer ações pedagógicas (SILVEIRA, 2018, p.121).

Na pesquisa de Castro (2017), por meio dos resultados encontrados, tanto em livros didáticos quanto em entrevistas com autores, a autora defende a ideia de que a pesquisa na internet não pode se desprender da questão ética e que livros didáticos, autores, professores e gestores devem trabalhar juntos na dimensão ético-pedagógica, que precede a punição e 
pode de forma potencial evitar a questão do plágio. A autora relata que "os autores não dão relevância ao plágio enquanto diretriz na organização do conteúdo dos livros didáticos e que delegam a tarefa aos professores em sala de aula" (CASTRO, 2017, p.109).

No que se refere o estudo de Krokoscz (2014), o conceito de plágio não tem apenas uma especificidade em termos do meio acadêmico comparado ao jurídico, mas também manifesta uma compreensão desatualizada de um fenômeno que não pode mais ser interpretado com as categorias que antecedem o surgimento de novas Tecnologias de Informações e Comunicações (TICs). Com isso, o referido autor realiza uma abordagem em forma de subsídios para um debate sobre o tema e para a caracterização da problemática relacionada ao processo de autoria científica. $\mathrm{O}$ autor supracitado ainda menciona que,

os estudos futuros em relação à autoria e ao plágio nos processos de produção textual científica deveriam explorar e aprofundar as reflexões e o debate sobre as correlações entre esses dois assuntos visando contribuírem para o desenvolvimento de uma conceituação atualizada sobre estes aspectos essenciais na produção científica (KROKOSCZ, 2014, p. 9).

Na dissertação de Freitas (2013), foi possível levar em consideração que as universidades precisam ampliar seus ambientes de discussão e preparação dos docentes e discentes, com vistas à construção da autoria, o que geralmente não ocorre, transferindo por parte dos acadêmicos do processo de reflexão e construção de suas próprias ideias. A referida autora ainda relata que "é necessário ampliar o leque de estratégias para superar as dificuldades e assegurar autonomia para os conhecimentos ali construídos. E esse é um movimento que não se constrói sem dar às referências socialmente circulantes a devida atenção" (FREITAS, 2013, p. 77).

Já na pesquisa de Dias (2013) foram apresentadas ponderações que tendem a minimizar os efeitos do plágio e possibilitar posições autoras autônomas, responsáveis e éticas, sendo proposto pela autora uma boa condução com domínio eficiente na pesquisa e orientações por parte dos docentes sobre a forma e o conteúdo da pesquisa. Assim, a autora finaliza sua dissertação trazendo reflexões que tendem a acreditar que "estudiosos da área de educação, pesquisadores, professores universitários, devemos 
nos atentar para o fato de que temos nossa parcela de responsabilidade neste processo da formação e constituição autoral" (DIAS, 2013, p. 144).

\section{Considerações finais}

[...] o plagiador cala a voz do outro que ele retoma [...], toma o lugar do outro indevidamente, intervém no movimento que faz a história, a trajetória dos sentidos (nega o percurso já feito) e nos processos de identificação - nega a identidade ao outro, e, em consequências, trapaceia com a própria (ORLANDI, 2004, p. 72).

Diante da pesquisa abordada e com o objetivo de realizar uma revisão integrativa a respeito do plágio, pode-se afirmar que entre os autores das pesquisas é considerada de forma unânime dentre as produções pesquisadas que os resultados apontam que se torna necessário e imprescindível a realização de novas pesquisas que visem complementar e dar continuidade com esta abordagem, devido à falta de material científico e para que seja aprimorado os conhecimentos. Vale ressaltar que a maioria das produções que foram selecionadas, mencionam sobre intervenções e que se busquem desenvolver estratégias de enfrentamento sobre o plágio na área educacional.

No que diz respeito às publicações realizadas por ano, percebese uma certa irregularidade e considerada insuficiência, demonstrando a necessidade de maior alcance de pesquisadores e grupos voltados a uma maior dedicação sobre o plágio. Sendo assim, ter acesso ao que já foi construído é, portanto, um grande desafio, uma vez que se percebe a necessidade de preencher lacunas na solidificação de conhecimentos cada vez mais atuais e presentes na realidade deste campo de atividade.

Pelas inúmeras oportunidades que surgem com as novas formas de divulgação de informações, torna-se um desafio para o docente convencer os seus alunos a não cometer plágio em seus trabalhos. É um procedimento de amadurecimento em relação ao conhecimento, uma vez que o aluno não foi preparado na sua trajetória escolar da educação básica e muito menos do ensino superior. $\mathrm{O}$ combate ao plágio nas produções acadêmicas parece 
tão fundamental quanto a qualificação e naturalidade do exercício de constituição da autoria. É impossível negar que é preciso tratar, discutir e prevenir o plágio entre os pesquisadores, sendo necessário mais pesquisas sobre o tema em questão

Espera-se que este estudo possa vir a auxiliar a desenvolver novas estratégias de combate do plágio, pensando em trabalhos futuros, principalmente no que se refere a área de ciências humanas, por considerálas extremamente relevantes para o meio acadêmico. Nesta seara, "permitir que vozes se calem, camuflem-se ou se diluam por intermédio do plágio é ser conivente com uma educação debilitada e com uma ciência fadada ao fracasso" (DIAS, 2013, p. 144)

$\mathrm{Na}$ esteira da finalização deste estudo, acreditamos ser de suma importância mencionar que a credibilidade do próprio trabalho científico fica afetada quando o plágio é praticado por pesquisadores. Assim, uma das possibilidades para o combate, portanto, seria apresentar discussões que contribuam para o combate ao plágio em pesquisas por meio de abordagens de conscientização.

\section{Referências}

BAZERMAN, C. Paying the Rent: languaging particularity and novelty. RBLA, Belo Horizonte, v.10, n.2, p.459-469, 2010. Disponível em: http:// wac.colostate.edu/siget/rbla/bazerman.pdf . Acesso em: 4 out. de 2021.

BRASIL. Lei no. 9.610, de 19 de fevereiro de 1998. Altera, atualiza e consolida a legislação sobre direitos autorais e dá outras providências. Diário Oficial da República Federativa do Brasil, Brasília [online], 20 fev. 1998. Disponível em: http://www.planalto.gov.br/ccivil_03/leis/19610.htm .Acesso em: 4 out. de 2021.

CASTRO, Rodrigues, Sirlene. A abordagem do plágio nos livros didáticos do ensino fundamental e na visão de autores. Mestrado em Educação. Universidade de Brasília - UnB, Brasília - DF, 2017. 
COSTA, Ana Luiza Santos da. Escrita, plágio e autoria em produções acadêmicas. Mestrado em Educação. Mestrado em Educação- Universidade Federal do Triângulo Mineiro - UFTM. Uberaba-MG, 2018.

DIAS, Wagner Teixeira. Vozes diluídas, camufladas ou exaltadas na fronteira entre a autoria e o plágio. Mestrado em Educação. Pontifícia Universidade Católica do Rio de Janeiro - PUC/RJ, 2013.

FARINA, Cassiamara. A percepção docente sobre as consequências do plágio para os processos de ensino e aprendizagem na universidade. Mestrado em Educação. Universidade Federal de Goiás - UFG. Jataí-GO, 2020.

FERREIRA, N. S. de A. As pesquisas denominadas "Estado da Arte". Educação \& Sociedade, 79, 257-272. 2002.

FREITAS, Talita Cristiane Sutter. Autoria e plágio: representações sociais na educação superior. Mestrado em educação. Universidade Regional de Blumenau - FURG. Blumenau - SC, 2013.

JUDENSNAIDER, I. O plágio, a cópia e a intertextualidade na produção acadêmica. Revista Espaço Acadêmico, Maringá, PR, v. 11, n. 125, p. 133138, abr. 2011a.

KROKOSCZ, Marcelo. Outras palavras: análise dos conceitos de autoria e plágio na produção textual científica no contexto pós-moderno. Doutorado em educação. Universidade de São Paulo - USP. São Paulo - SP, 2014.

LIMA, Mariana Batista De. Ctrl+c/Ctrl+v: plágio ou estratégia? representações de professores universitários sobre a escrita de seus alunos. Mestrado em Linguística Aplicada. Universidade Estadual de Campinas. Campinas - SP, 2013.

MENDES, K.D.S.; SILVEIRA, R.C.C.P.; GALVÃO, C.M. Revisão integrativa: método de pesquisa para a incorporação de evidências na saúde e na enfermagem. Texto \& Contexto Enfermagem, 2008.

SCHNEIDER, M. Ladrões de palavras: ensaio sobre o plágio, a psicanálise e o pensamento. Campinas: Editora da UNICAMP, 1990. 
SILVA, Obdália S. F. Entre o plágio e a autoria: qual o papel da universidade? Revista Brasileira de Educação v. 13 n. 38 maio/ago. 2008

SILVEIRA, Zélia Pires da. Plágio na academia: reflexões sobre a integridade na pesquisa e a ética na formação docente e discente. Mestrado em Educação e Docência. Universidade Federal de Minas Gerais. Belo Horizonte - MG, 2018.

SIMÕES, Alexandre Gazetta. O crime de plágio e suas variações no ambiente acadêmico. Âmbito Jurídico. Rio Grande do Sul, XV, n.96, Jan 2012. Disponível em:http://www.ambitojuridico.com.br/site/index.php?n_ link=revista_artigos_leitura\&artigo_id=11057. Acesso em: out. de 2021. 